\title{
Design of The Vehicle Door Structure Based on Finite Element Method
}

\author{
Tan Wei ${ }^{1,2}$,Wang Yan $^{2}$,Li Lingyang ${ }^{1}$,Zhang Yu ${ }^{1}$ \\ 1, Huazhong University of Science \&Technology, Wuhan, China \\ 2, Dongfeng Automobile Co.,LTD, Wuhan, China \\ E-mail: dfac_cae@126.com
}

\begin{abstract}
The performance of door assembly is very significant for the vehicle design. In the present paper, the finite element method is used in the development processes of the door assembly. The stiffness, strength, modal characteristic and anti-extrusion of a newly developed passenger vehicle door assembly are calculated and evaluated by several finite element analysis commercial software. The structural problems discovered by $\mathrm{FE}$ analysis have been modified and finally achieved the expected door structure performance target of this new vehicle. The issue in focus is to predict the performance of the door assembly by powerful finite element analysis software, and optimize the structure to meet the design targets. It is observed that this method can be used to forecast the performance of vehicle door efficiently when it's designed.
\end{abstract}

Keywords- ehicle Door, Structure, Strength, Stiffness, Modal, Anti-extrusion, FEM

\section{INTRODUCTION}

Door assembly is a very important part of vehicle cab. Performance as stiffness, strength and modal state of door structure shall be taken into consideration of door design, meanwhile, there is also a homologation requirement for door's anti extrusion aspect. This article is focused on researching the application on finite element analysis method during door assembly development, and elaborates how to evaluate door assembly from each aspect by using powerful finite element analysis software and optimizes the structures to have a new design proposal which meets all design targets.

A popular 3-D nonlinear dynamic explicit finite element (FE) code with advanced contact algorithms and material models was successfully used to simulate several types of armors subjected to the impact of projectiles moving at various velocities[1,2]. Augusto Cesar[3] used 6-Sigma tools to develop an experimental model that describes the system and he focused that the vibration observed at the top of rear door during normal opening operation, causing the impression of a fragile structure. A. Tuncer[3] constructed a test structure to imitate the vehicle door and the body and obtained the natural frequencies of the structure experimentally with and without seals lying between the two frames.

In this study, the author developed a methodology in the design of vehicle door. Firstly, the vehicle door model is established by Hypermesh. Then it is imported into Nastran for defining the boundary condition. For this purpose, a finite element model of the vehicle door is constructed and the material coefficients of the model are determined through the optimisation toolbox in Nastran. Nastran101 are used in linear static issues and Nastran103 for structural mode. Finally, the FEM model is solved by Ls-dyna after defining the boundary condition.

\section{DOOR STRUCTURE FINITE ELEMENT ANALysis}

After the completion of the first version of door structure design proposal (B2), CAD data shall be firstly transferred into the data which could be calsualted by finite element mode,including mesh dispersion, material definition and boundary condition setup etc. Then analyze and calculate the first edition finite element model, including four performance targets, which are model state, static stiffness, strength, and anti extrusion.

During the pre-process process, the requirement of mesh shape is as follows:

In finite element model, spot welds whose diameter is $6 \mathrm{~mm}$ is processed by connectors in Hypermesh which is created according to spot weld coordinates in CAD 3D model with quantity of welding layers set up and connectors of all spot welds uniformly recognized as Cweld element. Glue can be done by Area function in Connector. Eight-node element is adopted as glue element finally. The connecting elements between glue and panel is RBE3.

In finite element model calculated in NASTRAN, four nodes Cquad4 element is used as shell element, Cweld element is used as spotweld.

In the LS-dyan computing model, Belytschko-Tsay element type is used as shell element, Beam element is used as spotweld.

\section{A. Static vertical stiffness analysis}

The freedom of the installation hole where one end of the upper and lower door hinge fixed with the door frame is constrained at six directions, doors vertical deformation and stress distribution is calculated under two loading case using Nastran 101 solver. Nastran is controlled by the keyword to generate *. op2 file which can be transferred in Hyperview to gain the stress and displacement results. Max Vonmises stress of door shall be less than $0.23(\sigma \mathrm{s}+\sigma \mathrm{b})$ [1] in order to guarantee the durability of door under gravity. Max Vonmises stress of door shall be less than maximum yield strength of material in order to prevent permanent deformation of door from happening with $385 \mathrm{~N}$ loading on lock.

1) With 19 acceleration of gravity, calculate the maximum vertical displacement of the door and the stress generated on door sheet metal, See figure 1.

2) With vertical force of $385 \mathrm{~N}$ on door lock, calculate the maximum vertical displacement of the door and and the stress generated on door sheet metal, see figure 2 . 


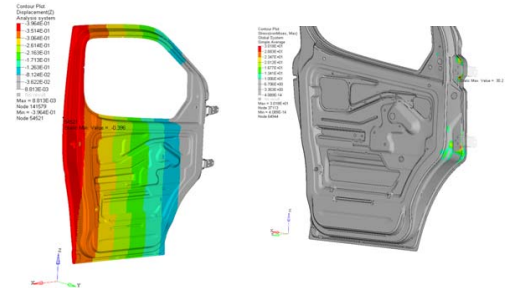

Figure 1. B2 Door deformation in gravity result

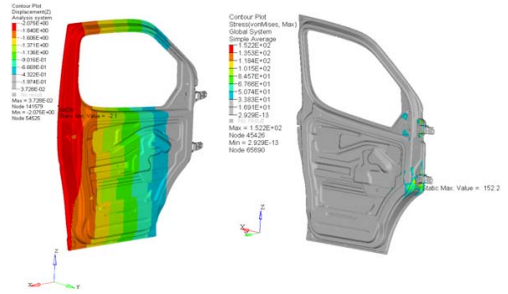

Figure 2. B2 Analysis result of of vertical loading on door lock

\section{$B$. Door torsion stiffness analysis}

The freedom of the installation hole where one end of the upper and lower door hinge fixed with the door frame is constrained at six directions and center of lock hole is constrained at $\mathrm{Y}$ direction. Torque $\mathrm{M}$ is applied to the center hole in the door lock, then calculate deflection angle $\theta 1$ and $\theta 2$ of highest and lowest nodes around the X-axis of the globe coordinates, the door torsion stiffness $T=\frac{2 M}{\theta 1+\theta 2}$ $\mathrm{Nm} /{ }^{\circ}$.
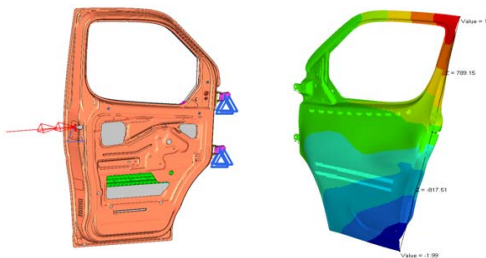

Figure 3. B2 torsion stiffness analysis result

\section{Door structure free modal analysis}

Modal is the natural vibration characteristics of mechanical structure, each modal has a specific natural frequency, damping ratio and mode shape. Solving problem of free vibration system characteristics (natural frequencies and modal shapes) is the problem which solves a matrix eigenvalue and eigenvector. In this paper, Nastran 103 modal solver is adopted to calculate the door modal and extract the first three orders of modal eigenvalue and modal eigenvector. Because the road excitation frequency to the vehicle is from 0 to $20 \mathrm{~Hz}$, four-cylinder inline diesel engine idling excitation frequency is $\mathrm{F}=650 / 30=21.7 \mathrm{~Hz}$, in order to separate the resonance frequency of the door away from the engine and road excitation frequency, the first order modal frequency of the door assembly at least greater than $21.6 \sqrt{2}=30.5 \mathrm{~Hz}$, Considering the influence on the modal frequency from door accessories,so the modal frequency of the door's sheet metal should be larger than $32 \mathrm{~Hz}$, Through modal analysis calculation, the 1 st order modal frequency of the door structure is $34.3 \mathrm{~Hz}$, which could meet the design requirements.

\section{Door side extrusion analysis}

Transitional degree of freedom of all the connecting points of the body and chassis on the extrusion side were constraint at three directions, the body skirt in the opposite side constraint the freedom at Y-direction; and there is a semi-column rigid body with its edge radius of $13 \mathrm{~mm}$; axis of the column plumbed; Loading the rigid column from the outside to inside along the Y- direction till the indenter's displacement achieves $457 \mathrm{~mm}$, and whose moving speed should be no more than $12.7 \mathrm{~mm} / \mathrm{s}$, and all this displacement process should be finished within 120 seconds.

This physical process can be considered as a quasi-static process, Ls-dyna solver is adopted for calculation and analysis, the force-time history information of the rigid column output into the results, and the rigid column force displacement curve (with circle mark ) could be plotted by the post-processing software of hyperview. According to Chinese standard GB15743-1995, in the phase of the rigid column displacement from $0-152 \mathrm{~mm}$, the counter force of the door to the rigid column should exceed the green solid line, in the phase from $152 \mathrm{~mm}$ to $305 \mathrm{~mm}$ in the process, the counter force should exceed the green dashed line, the peak counter force value of the rigid column should be more than $31.12 \mathrm{KN}$ during the whole phase.
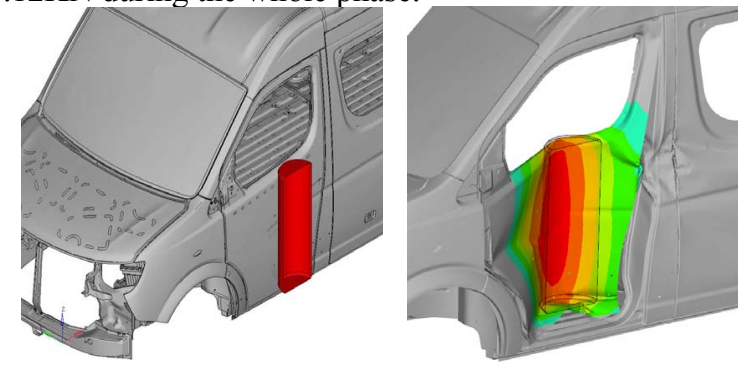

Figure 4. B2 door side extrusion initial \& finished time

Based on FEA result from proposal B2, strength,stiffness and modal performance all meet design requirements in this proposal. However, lateral extrustion performance is far behind the design requirement since the counterforce of rigid column hasn't met the legal requirement(red curve is lower than target line). In consquence, door structure needs to be revised. According to research on rigid column's counterforce curve during the process of lateral extrustion, the original collision beam bends in the beginning of extrustion, which means stiffness of collision beam is too weak to resist the load like above. Moreover it is quite hard to improve structure stiffness of interior and exterior door panel. For these reasons, the key point of optimizing door structure is to design a new collision beam structure with better stiffness under the condition of guaranteeing manufacture and assembly feasibility. 


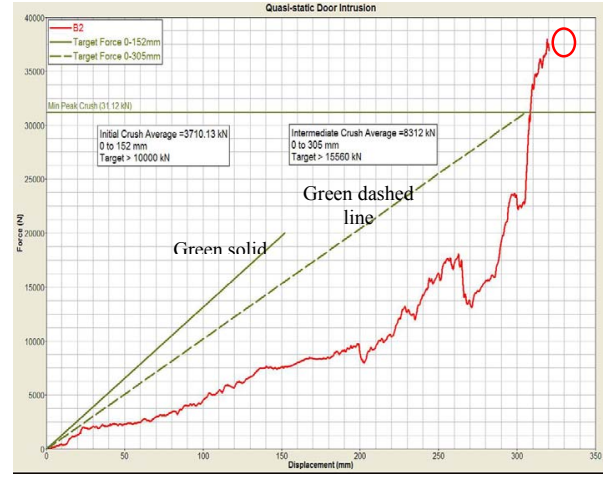

Figure 5. B2 rigid column counterforce-displacement curve

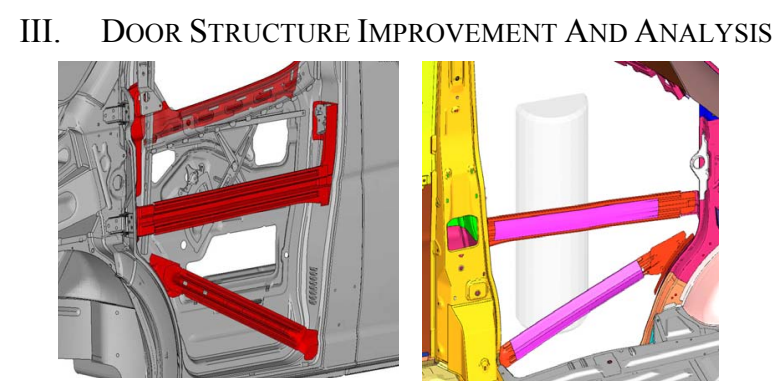

Figure 6. B25 proposal introduction (outside \& inside view)

In order to improve the stiffness of collision beam, Original horizontal collision beam has been moved upward with a new collision beam sideling supported underneath. Section of upper and lower collision beam has been changed into $\mathrm{W}$ shape with reinforcement plate welded inside, all of which formed a closed section.( Please see the Fig. 6 below). The thickness of collision beam and reinforcement plate is $3 \mathrm{~mm}$, height of upper collision beam reinforcement rib is $16 \mathrm{~mm}$, lower is $20 \mathrm{~mm}$, and lengths of upper and lower reinforcement plate are $700 \mathrm{~mm}$ and $600 \mathrm{~mm}$, respectively. Same 4 types of FEA have been adopted on B25 proposal, see sheet below.

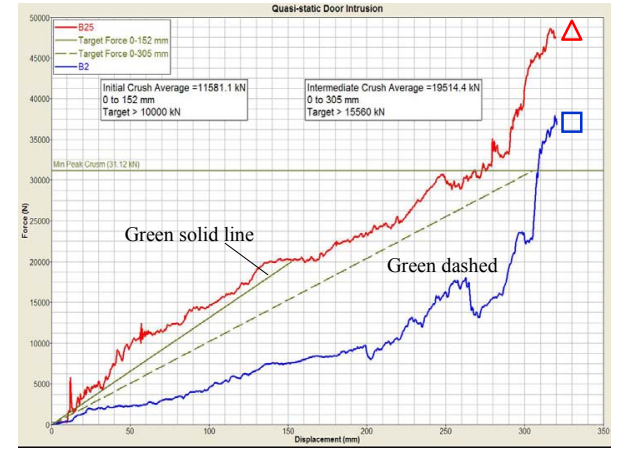

Figure 7. B25 Rigid column counterforce-displacement curve

From the finite element analysis shows, the rigid column counterforce curve with triangle mark in B25 proposal not only exceed the curve with rectangle mark in B2, but also above both of the green solid line and the dashed line, which meets the regulation requirements. And mean while the structural strength, stiffness and modal performance also achieves the target value.

\section{SUMMURY}

There is no physical test in the development process of this new vehicle door product, just using the finite element method to the discovery of design problems and be able to make targeted recommendations for improvement are very effective, quick guide engineer to improve the product qulity. this method can reduce prototype parts' producing and the number of physical tests to shorten the development cycle and reduce the development investment.

\section{REFERENCES}

[1]. H. Kurtaran, M. Buyuk. Ballistic impact simulation of GT model vehicle door using finite element method. Theoretical and Applied Fracture Mechanics [J], 2003.40, PP: 113-121

[2]. B.A. Gama, T.A. Bogetti. Aluminum foam integral armor: a new dimension in armor design. Composite Structures [J], 2001, 52(3-4), PP: 381-395.

[3]. Augusto Cesar Pinheiro de Araujo. Design of Experiments (DOE) and Other 6-Sigma Tools Used to Minimize Rear Door Opening Vibration on a Vehicle. SAE paper: 2003-01-3601

TABLE I. ELEMENT QUALITY REQUIREMENTS

\begin{tabular}{|c|c|c|c|}
\hline Num. & Comments & Criterion & Must \\
\hline 1 & Element Length - minimum & $\geq 5 \mathrm{~mm}$ & $\geq 4 \mathrm{~mm}$ \\
\hline 2 & Aspect ratio & $\leq 2.0$ & $\leq 3.0$ \\
\hline 3 & Warpage & $\leq 10^{\circ}$ & $\leq 15^{\circ}$ \\
\hline 4 & Jacobian & $\leq 0.6$ & $\leq 0.7$ \\
\hline 5 & Skewness & $\leq 45^{\circ}$ & $\leq 60^{\circ}$ \\
\hline 6 & QUAD element minimum internal angle & $\geq 45^{\circ}$ & $\geq 40^{\circ}$ \\
\hline 7 & QUAD element maximum internal angle & $\geq 135^{\circ}$ & $\geq 140^{\circ}$ \\
\hline 8 & TRIA element minimum internal angle & $\geq 30^{\circ}$ & $\geq 20^{\circ}$ \\
\hline 9 & TRIA element maximum internal angle & $\geq 120^{\circ}$ & $\geq 135^{\circ}$ \\
\hline 10 & Total number of triangles & $\leq 5 \%$ & \\
\hline
\end{tabular}


TABLE II. B2 ALL ANALYSIS RESULTS

\begin{tabular}{|c|c|c|c|}
\hline \multicolumn{2}{|c|}{} & Target & B2 \\
\hline \multirow{2}{*}{ Door vertical deformation in gravity } & Max Stress (Mpa) & $\leq 100$ & 30.2 \\
\cline { 2 - 4 } & Max Disp (mm) & $\leq 2$ & 0.4 \\
\hline \multirow{2}{*}{$385 \mathrm{~N}$ vertical force applying on door lock } & Max Stress (Mpa) & $\leq 180$ & 152.2 \\
\cline { 2 - 4 } & Max Disp $(\mathrm{mm})$ & $\leq 10$ & 3.5 \\
\hline \multicolumn{2}{|c|}{ Door Torsion stiffness $\left(\mathrm{Nm} /{ }^{\circ}\right)$} & $\geq 680$ & 725 \\
\hline 1st order door free modal frequency $(\mathrm{Hz})$ & $\geq 32$ & 34.3 \\
\hline \multirow{2}{*}{ The average force of lateral extrusion (KN) } & $0-152(\mathrm{~mm})$ & $\geq 10.00$ & 3.7 \\
\cline { 2 - 4 } & $0-305(\mathrm{~mm})$ & $\geq 15.56$ & 8.3 \\
\hline
\end{tabular}

TABLE III. B25 ALL ANALYSIS RESULTS

\begin{tabular}{|c|c|c|c|c|}
\hline & & Target & B2 & B25 \\
\hline \multirow{2}{*}{ Door vertical deformation in gravity } & Max Stress (Mpa) & $\leq 100$ & 30.2 & 75.5 \\
\hline & Max Disp (mm) & $\leq 2$ & 0.6 & 0.8 \\
\hline \multirow{2}{*}{$\begin{array}{l}385 \mathrm{~N} \text { vertical force applying on Door } \\
\text { lock point }\end{array}$} & Max Stress (Mpa) & $\leq 180$ & 152.2 & 159 \\
\hline & $\operatorname{Max} \operatorname{Disp}(\mathrm{mm})$ & $\leq 10$ & 3.5 & 1.7 \\
\hline \multicolumn{2}{|c|}{ Torsion stiffness $\left(\mathrm{Nm} /{ }^{\circ}\right)$} & $\geq 680$ & 725 & 725 \\
\hline \multicolumn{2}{|c|}{ 1st order modal frequency $(\mathrm{Hz})$} & $\geq 32$ & 34.3 & 34.3 \\
\hline \multirow{2}{*}{$\begin{array}{l}\text { The average force of lateral extrusion } \\
\qquad(\mathrm{KN})\end{array}$} & $0-152(\mathrm{~mm})$ & $\geq 10.00$ & 3.7 & 11.6 \\
\hline & 0-305 (mm) & $\geq 15.56$ & 8.3 & 19.5 \\
\hline \multicolumn{2}{|c|}{ The peak force of lateral extrusion $(\mathrm{KN})$} & $>31.12$ & OK & OK \\
\hline
\end{tabular}

